\title{
Measures to Reduce the Line Loss of Power Supply Enterprise
}

\author{
Yanhai Huang ${ }^{1}$, Yanjun Pang ${ }^{1}$, Bo Liu ${ }^{1}$, Jing Jin $^{1}$, Hong Zhang ${ }^{2}$, \\ Yuanda Zhu ${ }^{3}$, Huiyan $\mathrm{Cao}^{1}$, Chuang Wang $^{1}$, Yingying Yang ${ }^{1}$ \\ ${ }^{1}$ Fushun Power Supply Company, Liaoning Electric Power Company Limited, State Grid, China, \\ ${ }^{2}$ Jinzhou Power Supply Company, Liaoning Electric Power Company Limited, State Grid, China, \\ ${ }^{3}$ Techniques Training Center, Liaoning Electric Power Company Limited, State Grid, China
}

Keywords: Reactive Power Compensation; Line Loss; Transformer Loss; Measure; Copy the Acceptance Check Management

\begin{abstract}
With the development of economy, demand of energy has grown continuously for residents live and work in. The electric industry will obtain a bigger development space. The maintenance and management of the power system will also get the attention. Line loss and its management as an important way to maintain the normal and stable operation of power system played a huge role to push the social electric safety and the economic benefits of power supply. Line loss and its management must get the attention of power supply enterprise. This paper discusses the problems of line loss in power supply enterprise, and expounds the technical way to reduce power supply enterprise line loss and the organization measures of reducing line loss.
\end{abstract}

\section{Introduction}

Line loss is also called network loss, which refers to the form of heat energy loss, namely active power consumption of the resistance and conductivity. Reactive power also include a part of the loss, but this part of the energy loss is distributed in the form of magnetic energy by the line reactance, the reactance of the transformer coil winding and the inductive reactance of transformer core. Popular speaking, in the process of power transmission from the plant to the electric power users, line loss is the loss and damage generated by the transmission, substation, distribution and marketing of electricity. Line loss mainly is heating, the heating process is the process to convert electrical energy into heat energy. It not only caused power loss, but also raise the temperature of conductors, that will be aging insulation and shorten the service life, reduce the insulation strength, even cause thermal breakdown accident. Line loss waste energy and pollute the environment, and cause economic losses to the country ${ }^{[1]}$.

\section{The Existing Problems of Line Loss in the Power Supply Enterprise}

Firstly, reactive power management is not fully valued. The main performance is failed to effectively reactive power compensation for substations. Because reactive power optimization calculation work at above $10 \mathrm{kV}$ power grid has not be effectively carried on, which result in power grid reactive power optimization calculation never work in county company. There are quite a part of the enterprise did not to carry out the theoretical calculation of line loss, resulting in theoretical calculation of line loss is very weak. Line loss management lack practical theory basis.

Secondly, in terms of distribution transformer, the S9 energy-saving transformer has not be fully popularized. The S7 high energy consumption transformer is still used. It lead to load rate (at the maximum load) is very low, the three-phase load is unbalanced and capacity of substation is getting large, which often occurs in the running distribution transformer[2].

Thirdly, the company did not manage the measuring effectively, did not send the check table and standard meter in time. Not in accordance with the relevant provisions, rotation, and even some meter were not checked or replaced for a once in more than ten years.

Fourthly, the lack of a complete basic data and accurate power archives. Individual county sort out related data statements temporarily to cope with the inspection. Meters cannot correspond with 
area change accurately. Drawings also cannot conform with the situation, which was not be updated in time.

Fifthly, in the process of urban network transformation, the $10 \mathrm{kV}$ line transform is only paid attention to, but the transformation of the low voltage line under $380 \mathrm{~V}$ is ignored .At present, the old, messy, too long lines are the basic situation of running low voltage lines. These problems results in line loss increase, and produce a hidden danger.

\section{Technical Methods to Reduce Line Loss}

Firstly, booster to reduce line loss. If load power of the power grid transformed by booster remain unchanged, as long as to improve the voltage class, the load loss of the power grid components will reduce, the grid voltage will improve and the current of grid component will reduce accordingly, the load loss will reduce at the same time. Therefore, the booster can reduce the line loss effectively. In the implementation process, the booster transformation can be with the old grid transformation at the same time. In order to reduce the line loss of the power grid, the repetitive substation capacity and voltage grade should be reduced properly. Make the network connection simplify, and meet the needs of load growth. Concrete measures are: firstly, the shunt load, reduce the current density of lines. To the line with large load and high loss, the shunt should be transformed by made full use of substation remaining line space, at the same time the outlet line should be increased, in order to reduce line load, ultimately achieve the goal of reducing line $\operatorname{loss}^{[3]}$.Secondly, the load center is adjusted, the power grid structure is optimized. The $10 \mathrm{kV}$ power distribution network in rural exist a lot of problems, such as the radius of power supply is too long, and power point is too few .To achieve the purpose of saving electricity, construction of new stations and the method of reforming the old station will be taken to reduce the radius of power supply. Besides that take measures to reduce capacity, dense stationing, shorten the radius to save electricity of low voltage distribution in the countryside. The unreasonable line layout should be modified, to minimize the circuitous line and cut down the length of lines, thereby eliminating circuitous delivers. Use large section conductor on lines with smaller line diameter, too long operation time and high loss. Commonly use energy-saving main transformer, abandon the main transformer with high loss. According to the economy, putting into one or two operation for the substation with two main transformers. For the main transformer with load voltage regulation, timely adjust the voltage to keep it is in the qualified range. The loss of distribution transformer has a great influence on line loss. In rural network, the unsuitable product model, inappropriate choice of capacity, improper installation position will lead to cannot run economically. At the same time, there are running factors in rural distribution network such as stronger seasonal electric load, the large peak valley difference, low year utilization hours, underload for years, even without load too long, bad management. As a result, the important work content to reduce the power distribution network loss is reasonable type selection, and adjust the distribution capacity. Finally the average load rate of distribution is improved.

Secondly, to improve the measurement accuracy. To adopt the full electronic watt-hour meter with small error, high accuracy, small starting current, strong overload capacity and resistance to tilt, preventing electricity-stolen, low meter loss and the realized automatic meter reading management to replace the obsolete type watt-hour meter. In order to reduce the loss, improve the measurement accuracy and set the measuring point reasonably. Dedicated users should fit out and replace the missing-voltage recorder, and promote the electronic watt-hour meter actively with high precision and wide range. At the same time it eliminated the influence of artificial factors by installed the IC mater in some users, checked all kinds of measurement errors on site in time. To promote the application of centralized meter reading system, in order to read the distance meter for big users and residents. When reading mater every month, the power factor should be accounting timely for that month to judge if it is above 0.9.If there is insufficient, high-voltage measures to compensate should be properly adopted. When big users inspect the power factor during peak hours, reactive power meter with time sharing accounting can be installed ${ }^{[3]}$. 
Thirdly, to improve the power factor. By means of reactive power compensation device to improve the power factor. If the active power of the load remains the same, and increase the power factor of load. Not only can reduce the required reactive power of the load, but also reduce the reactive power out of generator and the reactive power through transformers and lines. Thereby it reduce the active power and power loss of lines and transformers ${ }^{[2]}$.

\section{Organization Measures to Reduce Line Loss}

Firstly, the statistics of line loss. Insist on the yearly implementation, the quarterly summary, the monthly assessment analysis. Make the management system of rewards and punishments fulfilled gradually. The line loss problems on management work should be found and solved in time. The company competent department should hold a line loss analysis meeting every month. regularly organize relevant personnel to analyze the completion situation of the index. In term of the quality of the line, the reactive power compensation, power theft and the meter connection, the circuit with higher line loss are discussed and analyzed. The relevant departments should implement actively, and report the search and process results of line loss problem at the next month meeting. The exist problems should be researched and solved.

Secondly, the reasonable arrangement of maintenance, clear the exist obstacles on lines in time, and shorten repair time as far as possible. So the quality of maintenance is improved. In addition, the transmission sector should pay attention to organize workers to clear line obstacles, wipe and maintenance line insulators in the spring and autumn season, to reduce the leakage phenomenon.

Thirdly, make the leadership strengthened gradually, further improved the network of line loss management, and to establish the line loss management responsibility system between department functions and productive department. To improve contract assess system of line loss, connection the indicators of line loss with the work quality of all the staff.

Fourthly, developing flow analysis and calculation actively. When the major way is changed, the best operating mode for flow calculation should be choosed in time to minimum its loss. To make full use of the dispatching automation system, work out the appropriate economical operation curve of the main transformer in each substation. In order to make sure each main transformer can operate in the condition of optimal or near optimal. To balance the reactive power, and improve the power factor of the user, which make the management of reactive power sent by local power plant generators and the reactive power through the transmission line, transformer strengthened. So the line loss is reduced, voltage quality is further improved, the transmission capacity of lines and transformers is improved gradually.

Fifthly, make the management of copy maters further strengthen, to plug up its holes. Make "metering management system". In accordance with the relevant provisions, the meter readers should finish his work, publicly announced the meter reading time and the meter reader. Competent department should organize spot check, to prohibit reading meter out of sync, the phenomenon of leakage copy or not copy, to achieve the timely and accurate meter reading, detailed and correct accounting.

\section{Conclusions}

There are lots of measures to reduce loss, to put the main first, put the targeted first, put real results first, and then measures simultaneously, to consolidate and expand the effect. In a word, for power supply enterprises, production safety is the absolute principle, to meet the supply growth, the standard of line loss, annual electricity is recycling and zero. The management to reduce the line loss is our work aim ${ }^{[1]}$.

\section{References}

[1] Xueqi Liao, Line loss calculation and line loss management. Beijing: Educational Science Press 1990. 
[2] Yilu Qi, Energy conservation and loss reduction technical manuals. Beijing:China Electric Power Press 1998.

[3] Ze Jin, Power saving technology and electricity saving project. Beijing:China Electric Power Press 1999. 